\title{
CLINICAL EVALUATION OF GLASS-IONOMER CEMENT RESTORATIONS
}

\author{
AVALIAÇÃO CLÍNICA DE RESTAURAÇÕES DE CIMENTO DE IONÔMERO DE VIDRO
}

\author{
Martin John TYAS \\ BDS, PhD, DDSc, GradDipHlthSc, FADM, FICD, FRACDS, FPFA, FADI, Professor in Restorative Dentistry, School of Dental Science, \\ University of Melbourne, Australia.
}

Corresponding address: Martin John Tyas - School of Dental Science - University of Melbourne, 711 Elizabeth Street, Parkville, Victoria 3010, Australia - Tel: + 61393410231 - e-mail: m.tyas@dent.unimelb.edu.au

\begin{abstract}
Tr This article mentions the general structure, properties and clinical performance of conventional and resin-modified glassionomer cements, focusing on adhesion, caries inhibition effect and recommendations of their use.

Uniterms: Atraumatic Restorative Treatment; Dental caries, control; Clinical evaluation; Glass ionomer cements; Longevity of restorations.
\end{abstract}

\begin{abstract}
RESUMO

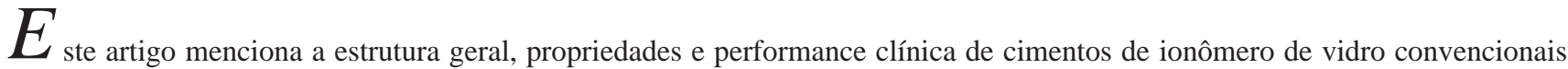
e modificados por resina, enfocando propriedades como adesão, efeito anti-cariogênico e recomendações de uso.

Unitermos: Tratamento Restaurador Atraumático; Cimentos de ionômero de vidro; Cárie dentária, controle; Avaliação clínica; Longevidade das restaurações.
\end{abstract}

\section{General structure and properties}

Glass-ionomer cements were developed by Wilson and McLean at the Laboratory of the Government Chemist in England in $1965^{27}$. They were a logical addition to the family of water-based dental cements, comprising silicate cement, zinc phosphate cement and zinc polycarboxylate cement. Since their commercial introduction, they are now available in essentially two types. 'Conventional' glass-ionomers consist of a fluoroaluminosilicate glass, usually a strontium or calcium salt, and polyalkenoic acid liquid, for example polyacrylic, maleic, itaconic and tricarbalyllic acids. The conventional materials sent by an acid-base reaction between the acidic liquid and the basic powder ${ }^{26}$. More recently, in order to improve the physical properties and decrease the water sensitivity of the conventional materials, the so called resin-modified glass-ionomer cements have become available. These contain a polymerisable resin, commonly hydroxyethylmethacrylate (HEMA), and therefore have the additional setting reaction of resin polymerisation, which may be self-cure and/or light-cure ${ }^{23}$.

The significant properties of the glass-ionomers are adhesion to calcified tooth structure, release of fluoride, minimal effect on the pulp, and that they are tooth-coloured. However, they are sensitive to dehydration early in the setting process, particularly the conventional cements, and they are brittle materials and therefore unsuitable for use in load-bearing areas ${ }^{26}$. In view of these properties, they have a wide range of uses, including fissure sealants, anterior approximal restorations, cervical restorations (both carious and non-carious), in deciduous teeth, as lining and luting cements, and as orthodontic band and bracket materials. A convenient classification of glass-ionomer cements is based on their clinical application. Type 1 cements are luting materials, Type 2 cements are restorative materials, and Type 3 cements are lining cements and fissure sealants ${ }^{26}$.

As mentioned above, one of the most significant properties of glass-ionomer cement is their adhesion to calcified tooth structure. The bonding mechanism of the conventional glass-ionomer is very complex, but consists initially of the wetting of the tooth surface by free polyacrylic acid, followed by ionic bonding between the carboxyl group in the cement liquid and calcium ions in the tooth structure. Recent work has established that a so-called 'ion exchange' layer is formed between the cement and the calcified structures, consisting of a complex of carboxyl, calcium and phosphate ions, derived from both the cement and from the enamel and dentine. This ion exchange layer is a few micrometres thick, and is an extremely strong, such that 
during bond strength testing, the glass-ionomer fails cohesively before the ion-exchange layer fails, and this complicates the interpretation of bond strength testing in the laboratory. It has also been suggested that there may be some bonding to collagen, but little research has been done in this area. In order to optimize the bond strength, most publications suggest conditioning the ${ }^{4}$ tooth surface with polyacrylic acid.

It appears that the bonding mechanism of the resinmodified glass-ionomer cements is different from that of the conventional materials, although research continues into this aspect. Because of the resin content of the former, there is the opportunity of bonding similar to that of the dentine bonding agents used in conjunction with resin composites. For example, conditioning the enamel results in a mild etch pattern, which allows some resin tag formation by a resin-modified glass-ionomer. Dentine conditioning also results in mild demineralisation together with the removal of some of the smear layer plugs. Thus, there may be a hybrid layer formation, together with the presence of tags in the tubules, which may enhance retention. Some authors have also demonstrated the ion-exchange layer, similar to that produced by the conventional materials. The common observation that resin-modified glass-ionomers have a higher bond strength to dentine than conventional glassionomers is probably because the resin-modified materials are fundamentally stronger ${ }^{25}$.

\section{Clinical performance}

Glass-ionomer cements have been the subject of numerous studies with respect to their clinical performance. Space does not permit a detailed consideration of all these studies, and it is therefore proposed to summarize the results related to the most common uses of the material.

\section{Adhesion}

Glass-ionomer cement is the ideal restorative material for non-carious cervical lesions, because of its adhesive properties and because the load on the final restoration is negligible. There have therefore been numerous studies on the performance of glass-ionomer in such lesions. Most non-carious cervical lesions are inherently not undercut, and the retention of the restoration depends on effective adhesion between the material and dentine. One of the longest observation periods for the conventional glassionomers in non-carious cervical lesions is by Matis ${ }^{12}$, who showed retention in the order of $90 \%$ after 10 years for KetacFil (Espe GmbH, Seefeld, Germany).

Because of the more recent introduction of the resinmodified glass-ionomer cements, only relatively short-term studies are available. Generally, retention rates have been as high as the conventional glass-ionomers, but some materials have shown problems with respect to colour stability. However, the resin-modified glass-ionomers have undergone steady development over the last few years, and therefore materials which are now being reported may not be representative of those which are currently on the market.

Resin-modified glass-ionomer cement can also be used as an adhesive layer for the retention of resin composite restorations, similar to the way in which the dentine bonding agents are used. The only commercial product which appears to be available for this use is Fuji Bond LC (GC Corporation, Tokyo). Clinical studies ${ }^{2,19}$ have shown a retention rates approaching $100 \%$ up to 5 years.

\section{Caries inhibition}

Glass-ionomer cements release fluoride; at a high rates initially, and then decreasing after a few days to a consistent low level for many years. Laboratory experiments using acidified gels, bacteria, enamel solubility methods and fluoride release experiments all suggest that glass-ionomers will have a low incidence of adjacent secondary caries. Unfortunately there are very few clinical studies which fulfill the requirements of a correctly designed trial to determine the anticariogenic activity of glass-ionomer ${ }^{20}$. Those studies which have been published are equivocal; about half show a benefit of glass-ionomer in preventing secondary caries, while about half show no such benefit.

\section{Effect on carious dentine}

Carious dentine can be divided into two zones; the zone closest to the pulp, termed the 'inner carious' or 'affected' dentine, and the zone closest to the oral cavity, termed the 'outer carious' or 'infected' dentine. These zones have different characteristics. The affected dentine has few or no bacteria, is brown-black in colour, is dry, and the collagen cross-links remain intact. Such dentine is therefore remineralisable, since it contains intact collagen which acts as a scaffold for the deposition of hydroxyapatite. In contrast, the infected dentine has a heavy bacterial load, the collagen is degraded, it has a pale yellow-brown appearance, is moist, and is non-remineralisable. Following the principles of minimum intervention cavity preparation, the affected dentine can be left in situ, with the potential for remineralisation under the effect of glass-ionomer cement. Several publications have now investigated the ability of glass-ionomer to promote remineralisation of the affected dentine, with promising data ${ }^{17}$.

\section{Fissure sealant}

One of the originally recommended uses for glassionomer cement was as a fissure sealant material, and it was evident that the fissure needed to be at least a $100 \mu \mathrm{m}$ wide in order to achieve penetration of the cement and protect it from occlusal load ${ }^{14}$. In those situations where the fissure is less than $100 \mu \mathrm{m}$ in diameter, which can be assessed using a sharp probe, it was recommended to open the fissure in order to obtain sealant penetration. Many clinical studies have identified the problem of retention of glass-ionomer fissure sealants. The traditional way of assessing the performance of fissure sealants in a clinical trial is by retention of the material. However, it is more appropriate to assess the protection against pit and fissure caries, and therefore the biological outcome is more important and more relevant than the physical outcome. Many studies have reported that the glass-ionomer fissure sealants appear to 
be lost from the fissure within several months of placement, however, using an impression technique, it has found that glass-ionomer cement may be retained in the depths of the fissure, but not be apparent at a clinical examination ${ }^{13}$. This explains the finding that the effect of glass-ionomer cement is generally equal to that of a resin-based sealant in preventing fissure caries, the resin sealant being visibly retained for several years.

\section{Deciduous teeth}

Glass-ionomer cements have received intensive investigation as restorative materials for deciduous teeth, and most of the trials have been done on the original conventional materials, with some on the more recent resinmodified products. In general, the results have been disappointing, particularly in a approximal cavities where the cement is relatively unsupported. Because of the brittleness of glass-ionomer cement, it requires support of the surrounding tooth structure, and therefore the performance is better in single-surface cavities compared to multi-surface cavities. In the mid-1990s, high powder:liquid ratio glass-ionomer cements were introduced, such as Ketac Molar (3M-Espe GmbH), Fuji IX GP (GC Dental Co) and Chemflex (Dentsply, York, PA). These materials are conventional glass-ionomers, but because of the high powder:liquid ratio, are somewhat stronger than the earlier aesthetic (Type 2) glass-ionomers. Clinical studies using the high powder:liquid materials have shown results which are much better than those of the early materials. For example, Rutar et al. ${ }^{21}$ used Fuji IX GP to restore occlusal and small approximal cavities in deciduous teeth. After 3 years, the results where favourable, with at least $90 \%$ Alpha scores for all United States Public Health Service criteria.

\section{Atraumatic Restorative Treatment (ART) technique}

Glass-ionomer cement is the material of choice in the Atraumatic Restorative Treatment (ART) technique. Several clinical trials of the ART have been published, showing that the survival rates of glass-ionomer cement are comparable to those of dental amalgam. Some of the conclusions which have been drawn from many ART studies include: the influence of patient age on the outcome is equivocal; there is a strong operator effect; single-surface restorations survive better than multi-surface restorations; there is minimum pain and discomfort; frequently no anaesthetic is necessary; the cost effectiveness is similar to amalgam; there is a need to evaluate the technique in patients with rampant caries $^{16}$. Details of the results of clinical trials of the ART technique have been presented elsewhere ${ }^{3,4}$.

\section{Tunnel and internal preparations}

The tunnel preparation was first proposed for use in deciduous teeth in $1963^{\circ}$. The materials of the day were silicate cement and amalgam, but because of their properties there was a high failure rate due to dissolution of the silicate cement and fracture of the marginal ridge. Following the introduction of glass-ionomer cement, Hunt ${ }^{6}$ and Knight ${ }^{10}$ almost simultaneously published a revised tunnel preparation design. Subsequently, Hunt ${ }^{7}$ introduced the internal preparation, which is similar in terms of access to the lesion, but does not penetrate through the enamel into the approximal space. The internal preparation is therefore suitable for those cases in which the enamel is porous but still intact, whereas the tunnel preparation is a possibility for those cases in which the approximal enamel is cavitated, but there is still adequate support for the marginal ridge.

Several clinical studies of the tunnel and the internal preparation have been published, with failure rates ranging from 9 to $50 \%$ at three years and $60 \%$ at 7 years ${ }^{5,9,18,24}$. The data on survival of tunnel restorations compared to minimal amalgam restorations are equivocal, but it does appear that internal restorations have a higher failure rate than tunnel restorations. The reasons for failure include fracture of the marginal ridge, cavitation in the approximal enamel in internal preparations, and secondary caries. It is very clear that both preparations are very demanding and require practice to be carried out competently.

\section{Cervical lining}

The so called cervical lining technique was first described by McLean and Gasser ${ }^{15}$ in 1985. In this technique the cervical portion of the approximal box of a posterior cavity is restored with glass-ionomer cement, and the final restoration being either resin composite or amalgam. It is usually indicated for posterior resin composite restorations, because cervical enamel is often a poor substrate for etching, the resin- dentine bond is technique sensitive, isolation from saliva and gingival fluid is difficult, and in addition it has been established that most secondary caries occurs at the cervical margin. In the cervical lining technique, sometimes called an 'open sandwich', these problems are overcome by having a radiopaque, adhesive, fluoridereleasing material in this area of high risk. The glass-ionomer cement used must be radiopaque for future detection on a radiograph, and from the practical viewpoint it is easier to place a conventional glass-ionomer rather than a resin modified glass-ionomer which requires photocuring. Several papers have been published on the long-term performance of cervical linings, with very encouraging results ${ }^{1,11,22}$. It is therefore recommended as a very viable alternative to the use of a dentine bonding agent in this area at high risk of microleakage.

\section{CONCLUSION}

Glass-ionomer cement is often known as a biomimetic material, because of its similar mechanical properties to dentine. This, together with the important benefits of adhesion and release of fluoride, render it an ideal material in many restorative situations. However, it's relatively poor mechanical properties must be appreciated, and therefore it should only be used as a final restorative material in lowstress areas, and it must be protected by resin composite or 
amalgam in areas of high stress.

\section{REFERENCES}

1- Andersson-Wenckert IE, van Dijken JW, Kieri C. Durability of extensive class II open-sandwich restorations with a resin-modified glass ionomer cement after 6 years. Am J Dent. 2004;17:43-50.

2- Burrow MF, Tyas MJ. Clinical evaluation of a glass ionomer-based dentine adhesive - 2-year results [abstract n. 2102]. J Dent Res. 1999;78(sp. Issue):368.

3- Frencken JE, Holmgren CJ. Atraumatic restorative treatment for dental caries. Nijmegen: STI Book b.v.; 1999.

4- Frencken JE, Van 't Hof MA, Van Amerongen WE, Holmgren CJ. Effectiveness of single-surface art restorations in the permanent dentition: a meta-analysis. J Dent Res. 2004;83:120-3.

5- Hasselrot L. Tunnel restorations in permanent teeth. A 7 year follow up study. Swed Dent J. 1998;22:1-7.

6- Hunt PR. A modified class II cavity preparation for glass ionomer restorative materials. Quintessence Int. 1984;10:1011-8.

7- Hunt PR. Rational cavity design principles. J Esthet Dent. 1994;6:245-56.

8- Jinks GM. Fluoride-impregnated cements and their effect on the activity of interproximal caries. J Dent Child. 1963;30:87-92.

9- Kinomoto Y, Inoue Y, Ebisu S. A two-year comparison of resinbased composite tunnel and class II restorations in a randomized controlled trial. Am J Dent. 2004;17:253-6.

10- Knight GM. The tunnel restoration. Dent Outlook. 1984;10:537.

11- Lindberg A, van Dijken JW, Lindberg M. 3-year evaluation of a new open sandwich technique in class II cavities. Am J Dent. 2003;16:33-6.

12- Matis BA, Cochran M, Carlson T. Longevity of glass-ionomer restorative materials: Results of a 10-year evaluation. Quintessence Int. 1996;27:373-82.

13- Mejare I, Mjör I. Glass ionomer and resin based fissure sealants; a clinical study. Scand J Dent Res. 1990;98:345-50.

14- McLean J, Wilson A. Fissure sealing and filling with an adhesive glass-ionomer cement. Br Dent J 1974;136:269-76.

15- McLean JW, Gasser O. Glass-cermet cements. Quintessence Int. 1985; $16: 333-43$.

16- Mjör IA, Gordan VV. A review of atraumatic restorative treatment (ART). Int Dent J. 1999;49:127-31.

17- Ngo H. Biological properties of glass-ionomers. In: GJ Mount, editor. An atlas of glass-ionomer cements. A clinician's guide. London: Martin Dunitz; 2002. p. 43-55.

18- Nicolaisen S, von der Fehr FR, Lunder N, Thomsen I. Performance of tunnel restorations at 3-6 years. J Dent. 2000;28:383-7.

19- Peumans M, Van Meerbeek B, Lambrechts P, Vanherle G. Twoyear clinical effectiveness of a resin-modified glass-ionomer adhesive. Am J Dent. 2003;16:363-8.
20- Randall RC, Wilson NHF. Glass-ionomer restoratives: a systematic review of a secondary caries treatment effect. J Dent Res. 1999;78:628-37.

21- Rutar J, McAllan L, Tyas MJ. Three-year clinical performance of glass ionomer cement in primary molars. Int J Paediatr Dent. 2002;12:146-7.

22- Sachdeo A, Gray GB, Sulieman MA, Jagger DC. Comparison of wear and clinical performance between amalgam, composite and open sandwich restorations: 2-year results. Eur J Prosthodont Restor Dent. 2004;12:15-20.

23- Sidhu SK, Watson TF. Resin-modified glass ionomer materials. A status report for the american journal of dentistry. Am J Dent. 1995;8:59-67.

24- Strand GV, Nordbo H, Leirskar J, von der Fehr FR, Eide GE. Tunnel restorations placed in routine practice and observed for 24 to 54 months. Quintessence Int. 2000;31:453-60.

25- Tyas MJ, Burrow MF. Adhesive restorative materials: a review. Aust Dent J. 2004;49:112-21.

26- Walls A. Glass polyalkenoate (glass ionomer) cements: a review. J Dent.1986;14:231-6.

27- Wilson AD, Kent BE. The glass-ionomer cement. A new translucent cement for dentistry. J App Chem Biotech. 1971;21:313. 